\title{
Review
}

\section{The Video Education Magazine}

What is Information Technology? Published by the Video Education Magazine Ltd., 15 Lyon Road, London SW19 2SB.

The Video Education Magazine was formed a year or two ago, with the idea of publishing on video cassette subject material which may be of some interest in education. It claims to produce videotapes that are valuable to school or authority based in-service training, and suggests that the emphasis is on schools and colleges at work which show ideas and methodologies in practice. I had a look at the tape entitled What is Information Technology?, not only because this is quite topical from the point of view of this journal, but also because I was interested in the level and methodology whereby such tapes are presented. The tape runs for about 41 minutes and 75 per cent of it is film of a talking head. In this case, the talking head makes a lot of sense as it happens to be that of Geoffrey Hubbard, the Director of the Council for Educational Technology. What Hubbard says during the course of this item of education, is something that would appeal to most. In a nutshell, he advocates that information technology in schools and colleges is at its best when helping teachers to 'do their own thing', rather than when it may be called upon to teach people how to program or about the technology itself. This is a lesson we are all learning, and one hopes is beginning to be learnt within schools and colleges. The 25 per cent of other visual material consists of either simple slide-like graphics or the odd picture of a classroom at work. It makes mention of Video Disk, Telecom Printing and Teletext which, if nothing else, gives one some idea of what these things are.

At the end of the exercise, however, I could not help feeling that this is not the best possible use of the medium. Videotapes are about showing things, not about saying things (although while showing, things need to be said). If one sets out with the idea of demonstrating to a teacher in a classroom that information technology is for him, or her, then one should concentrate on good examples of the art. A discussion between two people, no matter how clever the things they say are, is liable to become boring and not hold one's attention. The makers of tapes such as this have an enormous opportunity in front of them. However, the temptation to keep the productions cheap and simple by sticking with talking heads and stills, that every now and then illustrate what is being said, will lead them into a situation where they have only a very low market share. All one needs to do is to turn the television on on a Saturday morning in order to see the excellent way in which organizations such as the Open University can get their information across. This may mean that the producers will have to increase their investment in the production of tapes but, after all, this is an old story. The royal road to market share is quality, and quality is expensive, but at the end of the day this is the only way to get a return on investment in this sort of area.

Igor Aleksander 